\title{
Penggambaran Relief Cerita Pada Beberapa Candi Di Jawa Tengah Dan Timur (Makna Simbolis dan Edukatif)
}

\section{Hari Lelono}

Keywords: temple, meaning, relief, hindu-buddha, symbol, education

\section{How to Cite:}

Lelono, H. (2004). Penggambaran Relief Cerita Pada Beberapa Candi Di Jawa Tengah Dan Timur (Makna Simbolis dan Edukatif). Berkala Arkeologi, 24(1), 129-139. https://doi.org/10.30883/iba.v24i1.900

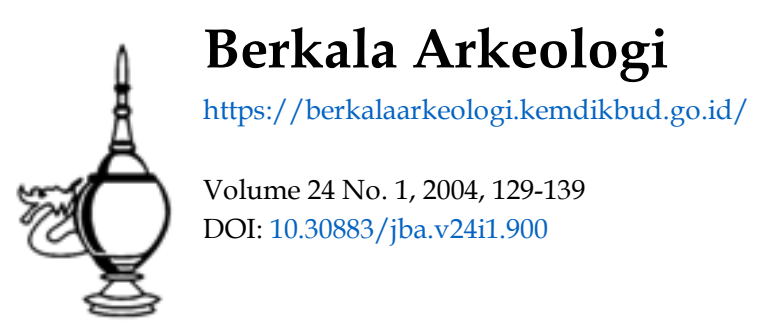

\section{c) (7)(2) (2)}

This work is licensed under a Creative Commons Attribution-NonCommercial-ShareAlike 4.0 International License. 


\section{Penggambaran Relief Cerita Pada Beberapa Candi Di Jawa Tengah Dan Timur (Makna Simbolis dan Edukatif)}

\section{Hari Lelono}

Keywords: temple, meaning, relief, hindu-buddha, symbol, education

\section{How to Cite:}

Lelono, H. (2004). Penggambaran Relief Cerita Pada Beberapa Candi Di Jawa Tengah Dan Timur (Makna Simbolis dan Edukatif). Berkala Arkeologi, 24(1), 129-139. https://doi.org/10.30883/iba.v24i1.900

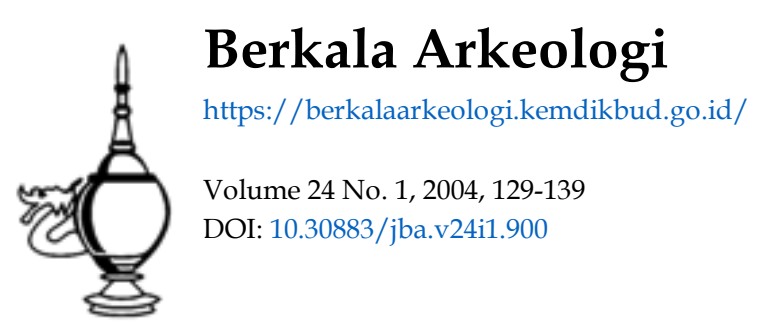

\section{c) (7)(2) (2)}

This work is licensed under a Creative Commons Attribution-NonCommercial-ShareAlike 4.0 International License. 


\title{
PENGGAMBARAN RELIEF CERITA PADA BEBERAPA CANDI DI JAWA TENGAH DAN TIMUR, (Makna Simbolis dan Edukatif)
}

\author{
T.M. Hari Lelono
}

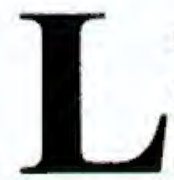

\section{atar Belakang Penulisan}

Candi-candi di Jawa Tengah dan Timur merupakan peninggalan yang sangat megah dan meyimpan banyak informasi tentang gambaran masyarakat masa klasik. Gambaran tersebut dapat dilihat pada pahatan relief yang biasanya menghiasi bangunan monumental tersebut. Oleh karena itu, melalui studi terhadap relief dapat mengungkap fenomena-fenomena sosial yang ada di dalam masyarakat Jawa pada masa lampau

Candi Borobudur, Mendut, dan Sukuh merupakan candi-candi di versi Jawa-tengahan, sedangkan Candi Jago, Surowono, Tigawangi, Kedaton dan Panataran merupakan candi-candi versi Jawa Timuran. Perbedaan utama dari segi arsitektur candi-candi tersebut terletak pada gayanya, gaya Jawa Tengah cenderung tambun, sedangkan Jawa Timur cenderung runcing. Pentatahan reliefpun terdapat perbedaan yang mencolok, gaya Jawa Tengahan cenderung digambarkan secara tiga dimensi, sedangkan gaya Jawa Timuran hanya dua dimensi. Hal yang sama pada seluruh candi tersebut adalah pada gaya penempatan relief yang selalu melingkari candi, baik sebagai ragam hias tetapi terdapat juga yang mengandung unsur cerita. Relief cerita dimaksudkan untuk menyampaikan pesan moral kepada masyarakat berupa ajaran keagamaan maupun ajaran kebenaran. Penggambaran relief pada bidang candi pun terdapat bermacam bentuk, ada bentuk yang menggambarkan tokoh-tokoh seperti Panji, Anglingdarma dan ada bentuk yang menggambarkan tokoh wayang. Penggambaran figur wayang inilah yang menarik untuk di uraikan.

Berkaitan dengan gambar relief yang ditatahkan pada bangunan candi yang berkaitan dengan fenomena-fenomena kehidupan masyarakat sehari-hari tersebut, tampaknya studi relief sangat menarik perhatian karena menggambarkan suatu fenomena sosial masa klasik, yang mengundang misteri untuk dilakukan penyelidikan lebih lanjut. Serangkaian penelitian telah banyak dilakukan oleh para ahli, namun belum banyak yang menggunakan pendekatan ethnoarkeologi. Ethnoarkeologi suatu disiplin untuk menguraikan dan memberikan penjelasan tentang suatu obyek/ fenomena masyarakat masa lalu dengan menggunakan anologi pada masyarakat masa kini yang mempunyai persamaan unsur dan polanya. Sedangkan anologi yang dimaksudkan 
adalah untuk memperoleh model kebudayaan yang dapat diproyeksikan pada kebudayaan masa lampau (Nurhadi, 1995: 8 - 9).

Oleh karena itu, makalah ini ingin mengungkap fenomena sosial masa klasik di Jawa yang menekankan pada salah satu aspek yaitu filosofis tokoh wayang dalam kehidupan masyarakat di Jawa.

\section{Metode}

\section{Pendekatan}

Sesuai tujuan penelitian, alur penalaran yang dugunakan adalah induktif, dengan tipe deskriptif.

\section{Jenis Data}

Data primer yang diperlukan dalam penelitian ini adalah relief cerita maupun noncerita yang menggambarkan figur-figur wayang. Sedangkan data sekunder (sebagai data pelengkap) berupa literatur, majalah yang berkaitan dengan relief/ wayang.

\section{Analisis Data}

Analisis data akan dilakukan secara kuantitatif dan kualitatif. Analisis kuantitatif berupa data relief yang tampak dipermukaan. Analisis kualitatif berupa uraianuraian untuk menjelaskan hubungan antara gambar wayang dengan nilai-nilai simbolisnya.

\section{II}

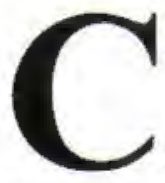
andi-Candi Hindu dan Budha di Jawa.

Tinggalan masa klasik yang bernuansa keagaman Hindu dan Budha pada sekitar abad VII - XV M berkembang dengan pesat. Beberapa tinggalan budaya tersebut berupa bangunan candi. Candi sebagai salah satu tempat untuk melakukan pemujaan keagamaan tersebut atau candi sebagai kuil (Soekmono, 1972: 241) dan pendarmaan raja-raja tertentu memiliki bentuk yang indah dengan bahan batu andesit maupun bata. Bahan candi di Jawa Tengah pada umumnya menggunakan bahan batu andesit hitam, sedangkan di Jawa Timur umumnya menggunakan bahan bata merah. Walaupun demikian, di Jawa tengah pada radius sekitar $15 \mathrm{~km}$ seputar Candi Borobudur banyak ditemukan candi-candi yang menggunakan bahan bata (Tjahjono, 2002: 2), seperti Candi Wurung dan Candi Bata. Sedangkan di Jawa Timur candi induk Penataranpun menggunakan bahan dari batu andesit, sedangkan di seputar situs Trowulan candi/ gapura menggunakan bahan batu bata. 
Candi secara arsitektural memiliki tiga bagian bangunan utama; yakni bagian kaki candi, bagian badan candi dan kemuncak (puncak) candi. Biasanya hiasan relief di tatahkan pada bagian kaki atau badan candi. Sebagai karya seni bangun mahatinggi dari para arsitek dan seniman masa lampau, maka untuk melengkapi dan memperindah candi pada bagian tertentu, misalnya pada bagian kaki, dan badan candi dihiasi dengan seni dekoratif dan penggambaran tokoh baik dalam bentuk manusia dan hewan. Karya-karya seni tersebut tentunya dibuat seindah mungkin mengingat bahwa candi adalah sebagai tempat suci sakral untuk melangsungkan upacara-upacara keagamaan dan pemujaan. Oleh karena itu, tidak mustahil jika para seniman pahat pada masa itu membuahkan maha karyanya untuk kebahagian para dewa dan raja-raja penguasa serta seluruh rakyatnya.

Di Jawa Tengah dan Jawa Timur, kadang dijumpai tatahan (relief) wayang, penggambaran berupa tokoh kesatria Pandawa Arjuna dan juga tokoh punakawan (abdi). Penggambaran para tokoh tersebut bukannya tanpa suatu maksud tertentu, hal ini berkaitan dengan latar keagamaan dan pesan-pesan simbolis yang ingin disampaikan oleh para seniman, berdasarkan pesan dari para penguasa dan tokoh keagamaan masa lalu. Selain itu penggambaran 'tokoh' binatang seperti di ambang pintu masuk Candi Mendut yang menggambarkan dua ekor burung bangau menerbangkan seekor kura-kura (bulus) menggunakan ranting. Sementara itu, dibagian bawah terlihat pemandangan anak-anak gembala dan pemburu dengan beberapa ekor kerbau sedang merumput. Para pemburu lengkap dengan busurnya sedang asyik bercengkerama sambil memandang ke angkasa... (Lelono, 2001). Adegan teresbut menggambarkan persahabatan antara burung bangau dengan kurakura (bulus) dimaksudkan untuk pesan moral kepada golongan masyarakat luas agar mudah dicerna terutama oleh anak-anak.

Penggambaran seluruh relief tersebut selain sebagai karya seni juga mengandung makna-makna tertentu. Panil pahatan pada dinding candi disengaja mempunyai makna. Tujuannya agar pesan yang disampaikan dapat dengan mudah diingat dan dicerna. Menurut Heru Satoto (1984) dalam konteks itu tentunya konsumen harus mempunyai latar budaya yang sama dengan lukisan panil itu. Sementara itu, makna simbolis, simbol berarti tanda atau ciri yang memberitahukan sesuatu kepada seseorang. Bisa berupa lukisan, perkataan, warna dan sebagainya, misal warna putih menyimbolkan kesucian atau keharuman. Padi melambangkan kesuburan atau kemakmuran. Binatang kancil menyimbolkan kecerdikan. Sedangkan penggambaran tokoh-tokoh wayang kesatria (Arjuna) menyimbolkan sifat orang yang jujur berani dan bertindak tegas. Raksasa melambangkan keangkeran dan angkaramurka suka milik orang lain (nepotisme dan korupsi) dan lain-lain.

Penggambaran tokoh-tokoh wayang dan 'tokoh' binatang pada beberapa candi di Jawa Tengah dan Jawa Timur tersebut diantaranya seperti di eandi: Prambanan, 
Sukuh, Penataran, dan Jago, memiliki makna dan arti simbolis tertentu yang diharapkan menjadi teladan bagi masyarakat pada masa itu. Sementara itu, pada masyarakat Jawa saat ini secara luas masih mengenal dan mencintai seni pertunjukkan wayang kulit dan dongeng-dongeng vabel, utamanya bagi generasi tua. Pertunjukan ini dipentaskan dalam acara tertentu seperti hajatan, slametan, dan pesta-pesta rakyat. Sedangkan cerita atau dongeng anak tentang sang Kancil, harimau, gajah, bangau dan kura-kura masih santer diperdengarkan oleh orang tua kepada anak-anaknya menjelang tidur sampai kurang lebih akhir tahun 1970-an, sebelum digantikan oleh cerita dan bentuk-bentuk audio visual dari budaya luar/ asing tentang kekuatan dan teknologi seperti tokoh-tokoh Satri Baja Hitam, Doraemon, Sincan dan sebagainya yang secara umum banyak hal bertentangan dengan nilai-nilai budaya yang kita miliki.

Beberapa candi sebagai contoh yang menggambarkan tokoh wayang dapat kita jumpai, seperti misalnya:

1. Candi Sukuh, di Karanganyar Jawa Tengah Candi Sukuh dibatasi sebelah utara berupa tebing yang curam dengan kedalaman kurang lebih 50 meter. Sebelah selatan merupakan dataran yang agak landai dan cukup luas, dan terdapat permukiman penduduk Desa Berjo. Sebelah timur merupakan punggungan kaki Gunung Lawu dengan ketinggian 3300 meter. Sebelah barat merupakan tebing yang dimanfaatkan sebagai pintu masuk ke bangunan candi. Candi Sukuh didirikan pada kurang lebih abad XV Masehi dengan adanya prasasti yang berbunyi "gapuro aban wong" dan "Gapuro buto amahut" diperkirakan kalimat tersebut berbunyi/ menunjukkan angka tahun $1359 \mathrm{Saka}=1437$ Masehi. Candi terdiri dari tiga bagian teras yang masing-masing dibatasi oleh tiga buah pintu. Teras pertama, terdapat gapura (paduraksa) dengan arsitektur yang mirip dengan pylon di Mesir (Stutterheim; 1930). Teras kedua dan ketiga terdapat gapura (candi bentar). Pada teras ke tiga terdapat tujuh buah (7) relief lepas yang menatahkan gambar wayang (mirip bentuk wayang di Bali) dengan cerita Sudamala dan di bagian lain terdapat cerita Garudeya, serta beberapa buah relief fauna, seperti gajah dan sapi. Relief cerita Sudamala mengisahkan bungsu dari Pandawa Sang Sadewa yang hendak dijadikan banten (tumbal) kepada Dewi Durga agar dunia dan alam semesta beserta isinya selamat (Lelono, 1995: 8), relief serupa juga terdapat di Candi Tigawangi (Pare Kediri).

2. Candi Mendut (Magelang), candi berlatar agama Budha dengan megah berdiri menggunakan bahan batu andesit pada bagaian luar tangga pintu masuk terdapat relief cerita Tantri yang digambarkan adegan kura-kura dengan burung bangau, dan cerita burung merak. Gambar-gambar serupa juga digambarkan pada bagain kaki candi Jago (Malang) yang menggambarkan cerita tetang buaya, pelanduk/ kancil, kerbau dan lain-lain. 
3. Candi Jago, terletak di Desa Jago, Kecamatan Tumpang, Malang. Berdasarkan Kitab Negarakertagama didirikan pada abad XIII sebagai tempat untuk pendarmaan Wisnuwardana. Adalah candi yang cukup megah bercorak budhis mengunakan batu andesit terdiri dari tiga bagian dan dikelilingi oleh relief cerita. Candi tersebut tentunya sangat penting, terbukti dengan adanya lima jenis cerita yang mengelilingi bangunan tersebut. Secara keseluruhan ada 144 buah panil cerita yang terdiri dari cerita: Tantri/ Anglingdarma, Kunjarakarna, Parthayajna, Arjunawijaya dan Kresnayana. Pada bagian kaki candi menghadap ke utara terdapat relief cerita Parthayajna (31 buah panil) yang salah satunya menggambarkan Arjuna diiringi oleh dua punakawan melihat seekor gajah putih yang muncul di tengah telaga (Lelono, 1996: 14).

\section{III}

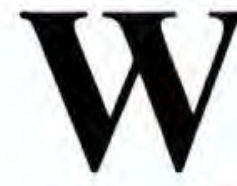

\section{ayang dan Simbolisnya bagi Masyarakat Jawa}

Pewayangan beserta segala perangkat yang ada di dalamnya, baik mengenai; cerita, gamelan, cara pementasan, cara memukul, irama gending, "lagon", dan sebagainya mempunyai berbagai fungsi. Pertunjukan wayang secara sepintas dapat kita ketahui, bahwa wayang adalah alat hiburan sekaligus merupakan perwujudan dari hasil budaya nenek moyang yang dilatari oleh konsep-konsep pemikiran dan kepercayaan tertentu. Selain itu juga merupakan salah satu sarana pendidikan yang sangat menarik karena disertai dengan peragaan. Cerita wayang banyak membentuk karakter, tidak heran jika banyak orang yang mengidolakan tokoh "pahlawan" dengan mengambil tokoh pewayangan.

Banyak petunjuk positif maupun negatif yang dapat kita peroleh dari cerita wayang, berbagai tipe watak digambarkan secara jelas, juga adanya ajaran moral tentang hukum karma. Misalnya cerita meninggalnya Dursasana, Pandita Durna, Salya, dan sebagainya merupakan penggambaran dari pada hukum karma tersebut. Falsafah Jawa tentang tingginya nilai prasojo digambarkan oleh tokoh Arjuna, Yudhistira, Sumbodro, dan lainnya. Falsafah harus menghargai orangtua maupun batur (pembantu), dan pengemis diwujudkan dalam penghormatan yang dilakukan oleh para satria Pandawa terhadap pumakawan (Semar, Bagong, Gareng dan petruk), bahkan kadang juga terjadi para raja/ satria yang menyamar sebagai pengemis, dan lain-lain. Falsafah 'jangan merendahkan orang cacat' (Sukrasana); Penggambaran watak dari tokoh-tokoh wayang yang mudah marah, mudah reda, tetapi jujur yaitu Baladewa; Penggambaran kstaria, berani dan benar, tidak pernah menghindari tanggung jawa antara lain: Bima, Gatutkaca, Sentyaki, dan lain sebagainya. 
Penggambaran tokoh-tokoh wayang yang bersifat negatif, seperti penggambaran sifat sombong diwujudkan dalam figur: Dursasana, Kartamarmo; watak kementhus yaitu Citraksi dan Citraksa. Sedangkan penggambaran tokoh wayang yang bersifat sebagai seorang pemimpin, pendidik dan pengayom, digambarkan oleh Begawan Abiyasa sering disebut dengan istilah tut wuri handayani adalah figur yang dalam mengasuh dan memberikan tauladan/ ajaran hidup kepada para cucunya Pandawa. Beliau digambarakn orang yang sabar dan tegas dalam membimbing para cucunya,m sehingga Pandawa dapat membawa rakyatnya sejahtera adil dan makınur.

Beberapa hal penting dalam seni wayang adalah: juru sungging, para juru sungging (pembuat/ penatah wayang) harus tahu betul setiap guratan yang ditorehkan pada sebidang kulit sapi, karena setiap guratan dengan berbagai bentuk dan variasinya itu memiliki arti dan makna yang berbeda-beda. Setiap wayang/ tokoh yang dihasilkan harus memiliki nilai budaya yang tinggi, dan tradisi para pembuat wayang tersebut sudah dimilikinya secara keturunan dari generasi ke generasi berikutnya dan syarat dengan berbagai aturan seperti; sesaji, melakukan puasa dengan bersemadi dan berpantang makan-makanan tertentu.

Dalam seni pertunjukan wayang komponen penting yang juga mengandung makna simbolis bukan hanya wayangnya saja, tetapi juga seluruh perangkat yang melengkapinya, antara lain:

1. Kelir (berupa layar dari bahan kain putih. Kelir digambarkan sebagai dunia tempat kita hidup.

2. Dalang menggambarakan 'Yang Menciptakan' dan 'Yang Menguasai Dunia',

3. Blencong (lampu minyak tanah) menggambarkan matahari.

4. Gedebog (batang pisang) menggambarkan bumi.

5. Wayang masuk kotak berarti orang-orang yang sudah tidak berperanan dalam masyarakat

\footnotetext{
IV

rti Simbolis Wayang

Secara umum cerita wayang pada prinsipnya menceritakan antara hal-hal yang baik dan hal-hal yang buruk yang dimanifestasikan dalam bentuk pertentangan antara Pandawa dengan Astina maupun tokoh Sabrangan lainnya. Keluarga Pandawa digambarkan sebagai tokoh yang berwatak jujur, antara satu saudara dengan yang lainnya (pandawa lima) saling melengkapi, mementingkan kesederhanaan, berbudi luhur, menghormati punakawan sebaik pelayan dan tidak kaya. Sebaliknya dalam tokoh-tokoh keluarga Astina dan semua ratu Sabrang merupakan simbolis dari kesombongan dan keangkaramurkaan. Tokoh Pandawa baik sebagai keseluruhan maupun secara terpisah-pisah merupakan tokoh ideal
} 
yang menjadi pelita kehidupan masyarakat kita dan dijadikan pedoman hidup. Sebagai contoh, apabila kita masuk ke rumah orang Jawa di pedesaan kadang ditemui wayang sebagai hiasan dinding ruang tamu. Hiasan yang dipajang misalnya tokoh Kresna, diharapkan tokoh tersebut dapat memberikan pengaruh/ inspirasi supaya penghuni/ pemilik rumah memiliki sifat-sifat seperti Kresna, yakni: jujur, cerdas dan berani bertindak, melindungi serta penyayom. Kresna adalah jelmaan Dewa Wisnu (awatara) sebagai dewa penyelamat/ pemelihara.

Berkaitan dengan arti simbolis dari para tokoh wayang tersebut, berikut ini akan diuraikan secara ringkas simbol-simbol yang dapat diketahui dari para tokoh Pandawa, sebagai berikut yang dapat dibagi menjadi empat tipe watak yaitu:

\section{Watak Yudistira}

Dengan bentuk dedeg, pakaian dan lain-lain akan segera dapat dimengerti maksud dan sifatnya. Dia adalah orang yang sabar, menguasai segala napsu, menerima segala watak dan kemauan orang lain. Ini diperlambangkan sebagai saudara tertua yang selalu berhati-hati dalam berbicara maupun bergerak, tidak pernah memukul, berjiwa ambeg para marta dalam arti suka menolong dan memberikan segala sesuatu yang dimilikinya kepada siapapun.

\section{Werkudara/Bima}

Bima adalah adik Yudistira, atau sebagai penghulu Pandawa. Tokoh yang berbentuk gagah perkasa, memiliki 'dedeg' (postur) yang tinggi mempunyai watak antara lain: berhati teguh, berkemauan keras, tidak mengenal kompromi bila belum yakin. Hati yang teguh digambarkan bahwa ia tidak dapat duduk, tidak dapat $n g o m o n g$ boso $0^{\circ}$ kecuali jika bertemu dengan Dewa Ruci sebagai lambang hati nuraninya.

\section{Arjuna}

Sebagai penengah Pandawa ia mempunyai ciri khusus sebagai lambang kesederhanaan, keindahan dan kehalusan budi. Sebenarnya sifat-sifat tersebut dimiliki Pandwa secara keseluruhan, tetapi sifat-sifat ini digambarkan secara lebih tegas dalam bentuk watak Arjuna. Arjuna terkenal dengan parasnya yang cantik, dilukiskan dalam bentuk bagian-bagian badan yang serba halus. Dari sifat-sifatnya itu digambarkan dengan pakaian yang paling sederhana, hampir tanpa perhiasan badan apapun. Di sinilah letak paling sulitnya wayang Arjuna, bila ada kekeliruan tidak bisa dikompensasi dengan pakaian yang digunakan.

\footnotetext{
- Tokoh ini tidak bisa berbicara halus, sesuai dengan tingkatan bahasa yang digunakan orang Jawa, misalnya basa ngoko= kasar; kromo madya-sedang; dan kromo inggil= bahasa halus.
} 


\section{Nakaula dan Sadewa}

Kedua saudara kembar tersebut lebih merupakan lambang dari pada penggambaran watak dari saudara kembar tersebut. Sebagai saudara bungsu sifat kembar memiliki atri filsafat, bahwa di dalam menerapkan filsafat hidup seperti yang digambarkan leh ketiga kakaknya harus secara kembar dalam arti serempak harmonis dan dilakasanakan secara berimbang antara semua sifat dan watak tersebut sehingga memudahkan dalam mencapai tujuan.

Apabila tokoh-tokoh Pandawa seperti telah dijelaskan di atas merupakan tokohtokoh ideal masyarakat, maka tokoh Sabrangan (orang luar) yang karena berbagai watak dan sifatnya menjadi tokoh yang tidak disenangi. Yang dimaksud dengan Sabrangan atau Ratu Sabrang adalah tokoh yang berasal dari luar yang meliputi semua musuh Pandawa, termasuk juga Astina. Tokoh Sabrangan lebih sering diwakili dengan bentuk raksasa, yang mempunyai sifat dan watak antara lain:

- Mengandalkan kekuatan fisik dan magis, tetapi tidak disertai dengan pengekangan hawa nafsu. Raja dan negara takluk disebabkan takut akan kekuatan fisik dan memiliki banyak tentara.

- Tidak berwatak ksatria dalam arti "mengumbar nafsu" baik cara hidup yang bermewah-mewah maupun dalam mengejar kekuasaan. Selain itu sering kita dengar dan lihat jika seorang raksasa sedang mengalami kesedihan akan selalu menangis, juga jika sedang dimabuk cinta.

- Bersifat materialistis, segala sesuatu diukur dengan kekayaan atau kebendaan, terlaksananya nafsu merupakan ukuran kepuasan. Misalnya; seorang raja yang melamar puteri cantik akan merasa pasti diterima jika dipinang dengan kekayaan materi.

Sifat dan watak yang antara lain telah tersebut di atas adalah sangat bertentangan dengan sifat dan watak para Pandawa. Jadi tokoh Sabrangan merupakan cerminan dari berbagai perbuatan yang tidak terpuji.

Dalam lakon pewayangan selalu ada punakawan. Punakawan tersebut adalah Semar, Gareng, Petruk dan Bagong sebagai abdi dari keluarga Pandawa; Togog dan Bilung adalah abdi untuk tokoh Astina. Peranan punakawan sebenarnya sangat sentral sebagai 'dewa kamanungsan' sangat menentukan setiap keputusan yang dikeluarkan oleh masing-masing keluarga (Astina - Pandawa) tersebut. Bila punakawan tidak setuju akan keputusan yang dilakukan, hal itu berarti akan mengalami kegagalan nantinya.

\section{Punakawan keluarga Pandawa:}

- Semar sebagai punakawan dilakukan dalam bentuk yang pendek merupakan gambaran seoarang abdi; dikiaskan dengan bentuk badan yang serba ganjil karena dadanya maju seperti perempuan, tetapi juga bentuk 
laki-laki karena mempunyai kuncung di atas kepalanya. Dengan bentuk yang serba ganjil dimasudkan agar selalu diperhatikan sehingga manusia akan selalu memperhatikan dan melaksanakan nasihat.

- Gareng dilukiskan dengan banyak keganjilan. Cara berjalan yang pincang dimaksudkan agar kita berjalan dan bertingkah laku harus hatihati, tangan yang pendek dan ceko (bengkok bagian persendian tangannya) memberi arti bahwa hendaknya selalu mengingat akan kekurangan dan keterbatasan kita.

- Petruk nama lainnya adalah Dawala atau dawa tur ala, karena digambarkan dengan bentuk hidung yang panjang, kaki yang panjang dan semua yang serba panjang. Ini mengkiaskan bahwa apabila kita menghendaki kesuksesan, segala sesuatu harus dipikirkan secara matang, dengan segala pertimbangan dan sebagainya.

- Demikian pula dengan figur Bagong yang dikiaskan dengan bentuk badan yang gemuk dan pendek, matanya yang besar, bibir yang tebal, dahi dan kepala yang besar pun mengkiaskan bermacam arti, seperti mau bekerja keras di tempat yang enak maupun tidak enak, tetapi jika diberi upah/ hadiah akan selalu mengunggul-unggulkan juragannya (Pandawa).

\section{Punakawan keluarga Astina:}

- Togog yang digambarkan dengan bentuk badan yang pendek, mulut yang lebar karena selalu mengeluarkan kata-kata untuk menahan sifat angkara murka, dan mata yang besar karena selalu digunakan untuk melihat segala nafsu kejahatan. Namun tutur katanya tidak pernah diperhatikan oleh bendara nya, maka tuannya selalu mengalami kegagalan dan lebih sering mengalami fatalisme.

- Bilung, digambarkan dengan badan kecil kurus mulut kecil tapi tajam, dahi agak maju, sifatnya suka menghasut/ adu domba dan selalu mementingkan diri sendiri, tidak mau hidup susah.

\section{V}

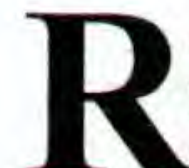
elief Candi sebagai Wahana untuk Menyampaikan Pesan Moral/ Edukatif kepada Masyarakat.

Candi sebagai bangunan suci pada jamannya pasti banyak diziarahi oleh masyarakat dan pemeluknya untuk melakukan serangkaian upacara ritual yang berkaitan dengan agama/ kepercayaannya. Masyarakat Jawa kuna tentunya tidak hanya melakukan ritual tetapi mereka juga akan mengamati segala sesuatu yang ada di bangunan tersebut, termasuk relief yang menghiasi candi.

Relief sebagai salah satu pelengkap/ hiasan, berfungsi juga sebagai media para penguasa khususnya bidang keagamaan untuk menyampaikan pesan-pesan yang 
berkaitan dengan keagamaan. Penggambaran reliefpun dikerjakan oleh para seniman seindah mungkin dengan mengacu pada segi estetika, sehingga dapat menjadi daya tarik dan menambah keindahan bangunan candi. Penggambaran relief cerita tentunya juga mengacu pada trend yang sedang popoler atau berkembang dengan cerita-cerita yang menarik. Pada umumnya penggambaran relief cerita wayang mengacu pada cerita yang sudah dikenal dan digemari masyarakat Jawa kuna pada masa itu. Selain karena cerita-cerita tersebut sangat tepat untuk menggambarkan dan memuat pesanpesan moral dan edukatif pada masyarakat. Cerita yang terkenal pada masa itu berkisar pada cerita Ramayana, Kunjarakarna, Parthayajna, Arjunawijaya dan Kresnayana.

Sekurangnya ada empat sumber Jawa kuna yang memberikan informasi adanya wayang kulit pada masa itu. Dalam hal ini tentunya bentuk wayang itupun telah mengalami berbagai perubahan bentuk yang tentunya disesuaikan dengan jamannya, tetapi tidak merubah substansi dari nilai-nilai simbolis yang dikandungnya. Sumbersumber yang menyebutkan adanya wayang pada masa Jawa kuna adalah: Kitab Arjunawiwaha, karya mpu Kanwa $(981$ c), Kitab Wrttasancaya gubahan mpu Tanakung (jaman Kediri), Kitab Bharatayuddha karangan mpu Sedah dan mpu Panuluh (1079 c), dan: Kitab Tantu Pangelaran yang tanpa diketahui pengarangnya (jaman Jawa pertengahan) (Riswanto, 1980:2).

Cerita-cerita yang bernuansakan Agama Budhis seperti cerita Tantri/ Anglingdarma ${ }^{\dagger}$. Khususnya dalam cerita Tantri, Anglingdarma digambarkan selalu dekat dengan dunia binatang dalam konteks ini adalah relief-relief binatang/ fabel. Cerita tersebut sangat digemari oleh anak-anak Jawa pada dekade tahun 60 sampai dengan 70 an lalu. Mengapa digemari?, karena bercerita tentang kisah-kisah jenaka, cerdik cendikia. Dalam relief digambarkan oleh tokoh-tokoh binatang seperti Sang Kancil, harimau, kepiting, gajah, kura-kura (bulus) dan lain-lain.

Dalam rangka mencari jatidiri bangsa dan untuk memperbaiki ahklak, salah satu cara dapat diacu dari warisan budaya nenek moyang kita sendiri melalui sumber-sumber sejarah dan arkeologi (relief). Salah satu aspek penting dalam relief yang kiranya perlu dikembangkan dan disebarluaskan utamanya cerita-cerita fabel dan simbolsimbiol yang tersirat dalam relief wayang. Cerita fabel sangat baik untuk memberikan bimbingan edukatif kepada anak-anak dan orang tua agar berbudi pekerti baik dan mengacu pada akar buidaya nenek moyang yang adiluhung.

\footnotetext{
${ }^{\dagger}$ Anglingdarma digambarkan sebagai seorang raja yang sakti mandraguna serta disegani oleh banyak lawan. Satu hal kelebihannya adalah dia mengerti bahasa binatang.
} 


\section{KEPUSTAKAAN}

Koentjaraningrat. 1969. Masyarakat Desa di Indonesia Masa Kini, Yayasan BP Fakultas Ekonomi UI, Jakarta.

1974. Kebudayaan, Mentalitet, dan Pembangunan, Bunga Rampai, PT Gramedia, Jakarta.

Lelono, Hari. 1995, Penelitian Pakaian dan Organisasi Sosial Pada Masa Klasik (Tahap II Jawa Tengah DIY), Laporan Hasil Penelitian Arkeologi (LHPA), Balai Arkeologi Yogyakarta.

1996. Penelitian Pakaian dan Organisasi Sosial Pada Masa Klasik (Tahap III Jawa Timur), LHPA, Balai Arkeologi Yogyakarta.

2001 Relief Candi Mendongeng Fabel, Intisari, PT. Intisari Mediatama, Jakarta.

Magetsari, Magetsari. 1995. Metode Penelitian Agama Dalam Arkeologi Seminar Nasional Metodelogi Riset Arkeologi. Paper, Depok 23 - 24 Januari 1995.

Mulyono, Sri. 1977. Simbolisme dan Mistiskisme dalam Wayang, sebuah Tinjauan Filosofis, Penerbit Gunung Agung, Jakarta,

1978. Wayang Asal Usul, Filsafat dan Masa Depannya, Penerbit Gunung Agung, Jakarta.

Riswanto, Hario. Wayang Dalam Lintasan Jaman Sebuah Tinjauan Kecil. Paper, Mata Kuliah Hinduisme dan Budhaisme, Fak. Sastra, UGM,

Soetrisno, PH. 1977. Filasafat Hidup Pancasila Sebagaimana Tercermin Dalam Falsafat Hidup Orang Jawa. Lembaga Pengembangan Masyarakat UGM, Penerbit Pandawa, Yogyakarta.

Soekmono. 1977. Candi Fungsi dan Pengertiannya, Disertasi, Universitas Indonesia. IKIP Semarang Press.

Tjahjono, Baskoro Daru. 2002. Latar Belakang Pendirian Candi Bata di Jawa Tengah, Laporan Penelitian Arkeologi (LPA). Balai Arkeologi Yogyakarta. 2002 